\title{
Política e poder na Antiguidade Tardia: uma ABORDAGEM POSSÍVEL
}

\author{
Renan Frighetto* \\ rfrighetto@hotmail.com
}

Resumo: Antiguidade Tardia ou Primeira Idade Média? O presente estudo pretende demonstrar, através de uma análise dos aspectos vinculados ao binômio política e poder, a viabilidade da aplicação do conceito "Antiguidade Tardia" para o período de transição entre os mundos clássico e medieval, ou seja, entre os séculos III e VIII de nossa era.

PalaVRas-Chave: Antigüidade Tardia, tradição clássica e imperial, monarquias romano-germânicas.

INTRODUÇÃO

Nam primum tibi mater Hispania est, terris omnibus terra felicior...

(Pac.,Pang.Theod.,IV)

Omnium terrarum, quaequae sunt ab occiduo usque ad Indos, pulcherrima es, o sacra semperque felix principum gentiumque mater Spania...

(Isid.,De Laud.Span.,1-3)

Aproximadamente dois séculos e meio separam as duas epígrafes que aparecem como praenotandum deste trabalho. Existem outras curiosidades relacionadas a elas que merecem nosso olhar mais atento: a primeira foi redigida nos ambientes cultivados e de tradição pagã da aristocracia senatorial galo-romana do sul da Gália pelo panegirista Pacato Drepanii, em honra do vitorioso Imperador Teodósio, no ano de 389, logo após a vitória militar deste sobre Magno Máximo, ocorrida no ano de 388, em Aquiléia. Já a segunda aparece no começo do De Laude

* Professor de História Antiga e Medieval da Universidade Federal do Paraná. 
Spaniae, de Isidoro de Sevilha, figura que integrava as mais altas dignidades episcopais católicas e personagem de grande importância política e cultural do reino hispano-visigodo de Toledo na primeira metade do século VII, tendo sido redigida entre os anos de 619 e 624, segundo a opinião de importantes filólogos que analisaram esta composição isidoriana (Rodriguez Alonso, 1975; Cazier, 1986; Fontaine, 2002).

Embora sejam escritos em tempos distintos, em espaços diferenciados e por autores que apresentavam divergências religiosas $\mathrm{e}$ dogmáticas, tanto a passagem do panegírico de Teodósio como a pequena parcela do De Laude Spaniae têm, a priori, um ponto em comum: o da glorificação e a elevação da Hispania, terra de origem tanto do grande Teodósio como o solar que acolheu e converteu os visigodos à "verdadeira fé", oferecendo àqueles as condições necessárias para a configuração de um regnum que se apresentaria como autentico defensor Christianitatis (Fontaine, 2002, p. 271-272). Além disto podemos observar outros interessantes elementos de convergência entre ambos os escritos, como o fato indubitável de que a unidade política ${ }^{1}$ estava diretamente vinculada à própria mater Hispania. Porém, nem Pacato, nem Isidoro foram completamente inovadores em apresentar a Hispania de uma forma tão positiva e favorável. De fato, antes deles já o haviam feito escritores da grandeza de Plínio ou de Floro, de Pompeu Trogo ou de Sílio Itálico, todos pertencentes ao universo daquilo que definimos como "mundo clássico".

Ora, com esse exemplo encontramo-nos diante daquilo que Momigliano definira como "interação cultural", acentuando a idéia de que o presente não pode, simplesmente, apagar o passado (Momigliano, 1970 , p. 94-95). Ou seja, tanto Pacato como Isidoro tinham conhecimento - e muito provavelmente tiveram diante de si manuscritos - da História Natural, de Plínio, e do Epitome da História de Tito Livio, de Floro, o que demonstra que em termos de pensamento existia uma sólida "ponte" entre o passado clássico e as realidades vivenciadas quer por Pacato, no século IV, quer por Isidoro de Sevilha, no século VII. Essas realidades, em nossa opinião, apresentam grandes similaridades e continuidades quando tratamos de analisar questões afetas ao amplo universo que compõe o binômio poder e política, sendo, por isso, esteio de um pensamento político clássico remodelado e adaptado por novas concepções ideológicas relacionadas ao Cristianismo. Continuidades, novas elaborações teóricas e Cristianismo, eis aqui elementos comuns e fundamentais para apresentarmos o período entre os séculos III e VIII como característicos da 
Antiguidade Tardia, num espaço diretamente associado à tradição política e cultural greco-latina, o mundo mediterrânico.

\section{CONSIDERAÇŌES}

Por um longo período, a historiografia latino-americana evitou utilizar o conceito de Antiguidade Tardia, mantendo-se fiel à tradicional divisão temporal que apresentava aquela como integrante da Alta Idade Média. Nesse caso, o preceito da ruptura entre o mundo clássico e o medieval aparecia como evidente e natural: afinal de contas, segundo esse raciocínio, o Império Romano Ocidental acabara de forma abrupta e irreversivel, o Imperator deixava de ser realidade nos territórios ocidentais, e os "bárbaros", principais responsáveis pela derrocada romana, impuseram sua vontade em termos políticos e culturais. Contudo, tal perspectiva "negativa", que segue em boa medida algum comentário de Jerônimo, ou mesmo uma parcela inicial do relato de Hidácio de Chaves, deve ser cuidadosamente matizada, pois nem o Império Romano do Ocidente desapareceu in toto, tampouco a idéia ou as virtudes relacionadas ao Imperator, assim como as tribos que se fixaram no interior dos territórios imperiais, não foram as grandes responsáveis pela fragmentação interna do Império, em sua Pars Occidentalis. Quiçá um dos maiores entusiastas dessa forma de interpretação, mais interessado em buscar as conexões políticas e culturais dessa "nova antiguidade" com a tradição republicana e imperial clássicas, tenha sido o Prof. Johannes Straub (1990, p. 649-667), contemporâneo do anteriormente citado Arnaldo Momigliano e de Henri Irinee-Marrou (1970, p. 60-87), com os quais partilhava sua visão sobre a força da tradição que legitimava os detentores do poder político no campo ideológico. Assim, podemos dizer que o conceito de Antiguidade Tardia vai bem mais além da simples visão da estética e do vestuário, revestindo, inclusive, a construção entre os séculos III e VIII de um preceito político-ideológico que conectava elementos da tradição política clássica imperial romana, a necessidade e a legitimação daquela forma de poder monárquico com as construções teóricas que indicavam a relação entre a centralização do poder e as práticas religiosas de cunho monoteísta, seja de procedência pagã, seja de procedência cristã.

Tal perspectiva ideológica pode ser rastreada através da análise das fontes históricas, mais que num simples olhar dos comentários realizados pela historiografia do século XX. Com efeito podemos observar que nas fontes cristãs - como o De mortibus persecutorum, de Lactancio, 
ou as histórias, de Paulo Orósio e de Isidoro de Sevilha - e nas fontes pagãs, como o De Caesaribus, de Aurélio Victor, os panegíricos latinos a a seqüência de vários autores da Historia Augusta, encontramos pontos comuns que indicam um denso processo de continuidades, permanências e intercâmbios políticos e culturais entre obras, a princípio, antagônicas.

Um primeiro exemplo dos contatos existentes entre as fontes cristãs e as pagãs pode ser observado a partir da descrição oferecida por aqueles relatos dos ritos que acentuavam a associação entre o governante e a sua condição sacra. Ou seja, da prática da adoratio à figura do imperador, característica por certo vinculada ao período do Dominato, em que o soberano incorporava e aceitava reverências quase divinas, afastando-se do modelo de princeps proposto desde Augusto e aproximando-se mais do protótipo do monarca helenístico. Em tom de crítica, o pagão Aurélio Victor, oriundo da província da África, referia-se ao Imperador Diocleciano como um homem de origem humilde que se deixara levar "por um espírito cheio de orgulho", incomum ao verdadeiro cidadão, a tal ponto que, segundo o historiador pagão, "foi o primeiro de todos depois de Calígula e Domiciano que permitiu ser chamado 'senhor' publicamente, ser adorado e ser invocado como um deus" (Aur. Vic. De Caesaribus, 39). Parece-nos indubitável que Aurélio Victor seguia, ao referir-se a Calígula e Domiciano, uma linha de repreensão - poderíamos até mesmo afirmar de reprovação -, característica da literatura pró-senatorial presente em Tácito e Suetônio (ANDré; Hus, 1974, p. 108-110), que lançara uma damnatio memoriae sobre aqueles imperadores em razão de suas atitudes despóticas que incluíam, certamente, sua adoração quase divina. Nunca é demais recordar que no universo político-cultural greco-latino, desde o período clássico, a tendência à auto-adoração divina era entendida como prática de incultos, de não-civilizados, sendo esta a verdadeira crítica que Aurélio Victor dirigia a Diocleciano.

Nessa mesma direção encontramos a crítica do cristão Lactâncio ao Imperador Galério, sucessor de Diocleciano como Augusto na Pars Orientalis do Império Romano, nos primórdios do século IV. Também em tom de damnatio memoriae à figura de Galério, acusado de ser o verdadeiro responsável pela "grande perseguição" contra os cristãos nos territórios orientais entre 303-311, Lactâncio informava que, após a vitória sobre os persas, Galério tentou introduzir uma "norma e costume que os súditos se entreguem ao serviço dos reis como escravos e que os reis se sirvam de seu povo como de escravos de sua própria casa" (Lact., De Mort. Persc., 21, 2). É provável, como bem acentuaram Teja (1999) e 
Bravo (1997), que nessa passagem tenhamos uma clara referência da prática da proskinesis, da reverência característica entre os persas já descrita por Heródoto (Herod., Hist., VII, 136) e integrada no âmbito da adoratio latina, entendida como cerceadora da eleutheria, da liberdade.

Mas, como já observamos em Aurélio Victor, tal prática já vinha sendo utilizada por Diocleciano e, certamente, por imperadores que o antecederam. Seria o caso de Aureliano que, de acordo com Flávio Vopisco - um dos biógrafos que integram a Historia Augusta -, estava diretamente relacionado ao culto do Sol desde o seu nascimento, quando a púrpura e a coroa apareceram como signo de seu futuro imperial (Flav. Vop., Div. Aurel., I, 3). Notamos, com isso, que, nos autores do século IV, sejam cristãos ou pagãos, existem elementos comuns relacionados ao pensamento político e que ainda idealizam o modelo de soberano mais próximo da realidade do período alto-imperial. Uma perspectiva notoriamente anacrônica, por certo, mas que nos indica a sobrevivência das idéias políticas do período clássico nesse momento de transição, embora seja igualmente um sinal inequívoco da tendente sacralização da figura do imperador, que tinha como objetivo prioritário reforçar o seu papel de catalizador e centralizador do poder político no mundo imperial romano.

Apesar da crítica realizada por autores pagãos e cristãos dessa prática de adoração, i verência e distinção da figura do imperador, elevando-o a uma posição quase divina, que o enyolvia num ambiente misterioso e restrito aos mais destacados membros do consistorium imperial (TejA, 1999, p. 42-43), o certo é que os imperadores da quarta centúria, no ocidente ou no oriente do mundo imperial romano, preservaram e potencializaram o culto da adoratio/proskinesis. Os exemplos de Constantino, Constâncio, Juliano e Teodósio, amplamente analisados pela historiografia contemporânea, bem como pelos relatos, favoráveis e desfavoráveis segundo o sistema ético do observador (FinLEY, 1985, p. 67) e também pelos motivos que levaram à composição de determinada obra - de autores como Eusébio de Cesarea, Ammiano Marcelino, Paulo Orósio e dos já mencionados Lactâncio, Aurélio Victor e os panegiristas latinos da Gália -, revelam a manutenção dessa práxis, que, sem qualquer dúvida, está relacionada à necessidade da concentração e centralização dos poderes políticos à volta de um Imperator que fundamenta seu poder ideológico em sua condição de Sacratissimus. Essa construção ideológica mostranos, também, um grave problema herdado da "crise" do sistema institucional da polis/ciuitas da segunda metade do século II: o desrespeito ao 
poder imperial centralizado, que acabava por gerar contestações visíveis nas ações tirânicas e usurpatórias ocorridas desde o século II e mantidas vivas ao longo da Antiguidade Tardia. Quiçá possamos pensar na força de poderes de cunho regional e local, que, sendo alijados das decisões políticas tomadas na Corte Imperial, rebelavam-se contra esse esquecimento (FrighetTo, 2002a). Alguns poderiam entender essa atitude como "forma de ruptura", mas deve-se ter em consideração que uma posição de força seria benéfica para futuras negociações num mesmo patamar de igualdade, além de ser importante frisar que questionamentos ao poder centralizado existiram, como mínimo, desde o período helenístico.

Um exemplo pode clarificar essa argumentação: entre 383 e 388, o Império Romano teve três imperatores nominalmente legítimos, Magno Máximo, no eixo Britania-Galias-Hispania, Valentiniano I, na Itália, e Teodósio, nos territórios orientais. De acordo com Maria Vitória Escribano (1990, p. 260-262), houve, inclusive, um reconhecimento inicial da usurpação de Magno Máximo por parte dos outros dois imperatores, na medida em que o usurpador vitorioso contava com a aclamatio imperii das legiões romanas dos territórios ocidentais. Portanto, parece evidente que a força dos apoios político-militares tinha uma efetividade real com relação às construções teóricas e legitimadoras (FrigheTTo, 2004c, p. 41 42). Assim, a aristocracia senatorial de origem romana fixada naquelas áreas dominadas pelo usurpador Magno Máximo via nesse chefe militar de origem hispana o interlocutor de suas necessidades junto às cortes imperiais de Milão e Constantinopla.

O rompimento dessa confiança começa a parecer mais evidente a partir de 385 , com a execução de Prisciliano e alguns de seus partidários em Treveris, que poderiam, com muita probabilidade, ter conexões clientelares e de parentesco com Teodósio (Escribano, 1990, p. 267). Chama a atenção o total silêncio de importantes fontes, como Orósio e Zózimo, sobre a questão priscilianista e que pode ter relação com a otimização de Teodósio como Princeps Christianus Sacratissimus, enquanto a única citação direta dos acontecimentos é o relato de Sulpício Severo que parece mostrar-nos a tentativa de Magno Máximo de buscar apoio e reconhecimento para sua causa junto a Ambrósio de Milão (FrighetTo, 2005b).

Ora, nota-se, portanto, que a construção ideológica da "monarquia ideal" nos primórdios da Antiguidade Tardia passava, necessariamente, pela união dos elementos teóricos relacionados à tradição clássica grecolatina e suas "novas" interpretações cristãs, que visavam reforçar o poder político e centralizador à volta do Imperator. Contudo, a força dos poderes, 
de cunho regional, daquelas aristocracias de origem romana, que detinham significativo prestígio político-militar em suas áreas de estabelecimento e influência, surgia como contraponto da proposta de unidade imperial que seria enormemente potencializada com a chegada e fixação nos territórios imperiais dos grupos migratórios de origem germânica no final do século IV.

Essa "novidade" pode ser interpretada de duas formas: uma, mais tradicional, que lança sobre esses "novos" grupos migratórios a responsabilidade pelo enfraquecimento político-institucional do Império Romano em sua Pars Occidentalis e sua conseqüente desaparição no final do século V; e outra, que busca verificar a paulatina integração entre os clãs nobiliárquicos desses grupos recém-fixados com certos segmentos das aristocracias regionais de origem romana e a tentativa dos primeiros de assumir uma posição de destaque e substituição da já frágil autoridade imperial (Frighetto, 2000; Rouche, 1979; Perez SANCHeZ, 1989).

Dessa forma temos a primeira perspectiva como um exemplo típico de ruptura, atualmente muito contestada por diversos segmentos historiográficos, enquanto a segunda perspectiva passa a idéia de que os germanos terminaram por adotar grande parte da tradição político-institucional do mundo imperial romano. Provavelmente é nessa linha interpretativa que aparece a afirmação de García Moreno (1989) da "vitória" da monarquia na Antigaidade Tardia. Parece-nos certo que o historiador espanhol referia-se ao estabelecimento e à institucionalização entre os germanos da monarquia de tipo clássico, baseada na tradição imperial romana. Vale recordar que Aelio Spartianus, em sua Vita Hadriani, integrada na Historia Augusta, revelava a intenção do Imperador Adriano de levar a monarquia praticada entre os romanos aos germanos, para, com isso, integrá-los ao Orbe civilizado greco-latino (Ael. Spart., Vit. Hadr., 12).

Essa idéia demonstra a intensa relação entre romanos e germanos, apresentada igualmente por Tácito, do ponto de vista político e cultural nas regiões limítrofes do Império Romano. ${ }^{1}$ Por outro lado, seguindo as observações legadas pelas fontes tardo-antigas de procedência grecolatina, essa perspectiva seria compartilhada pelos lideres clânicos de origem germânica, interessados na aproximação ao ideal político e civilizacional greco-latino que os incluiria como integrantes e participantes daquela tradição. Como recentemente indicamos (FrIGHETTO, 2005c), esse processo de adoção de uma monarquia ao estilo imperial mais estável pelos germanos foi lento e paulatino, sendo o modelo hereditário legado por 
Teodósio um exemplo interessante e que deixou marcas indeléveis para os futuros monarcas romano-germânicos.

A recepção da monarquia de tipo clássico entre os germanos trouxe uma série de novas interpretações, que diferiam e muito da imagem "marcada" por Tácito na virada dos séculos I e II de nossa era: de chefes guerreiros eleitos apenas em casos de guerra, para conduzir o povo em armas - grupos que na perspectiva clássica viviam da guerra e de forma nômade -, passaram a uma condição de interlocutores entre seu povo e as autoridades imperiais, bem como de responsáveis, na posição de aliados do Império Romano, pela defesa de determinadas áreas nas quais foram estabelecidos e fixados por meio de pactos de federação e auxílio - o foedus (FrighetTo, 2002a).

Em termos gerais, contemplamos aqui dois dos elementos básicos e constitutivos da noção de monarquia clássica: a autoridade reconhecida e legitimada - em muitos casos, através da utilização da força sobre todo o grupo político - e o estabelecimento de certos limites territoriais para o exercício do poder, e que poderia ser extensivo a outras regiões sob a forma de hegemon, através da relação estreita entre membros das aristocracias regionais de origem romana e os elementos da nobilitas germânica. Citaremos como exemplo o caso que melhor conhecemos, o visigodo, alertando para a possibilidade de que outros exemplos possam ser igualmente enquadrados nesse mesmo panorama, mas sempre ressaltando as especificidades inerentes a cada caso e que terminam tornando-os semelhantes, porém nunca idênticos.

Como sabemos, a relação entre romanos e godos sempre esteve marcada por momentos de aproximação, como nos relata Iulii Capitolini, na Vita Maximini Duo, ao referir-se às atividades comerciais existentes na fronteira da Trácia (Iul. Cap., Max. Duo, 4), ou de conflitividade, como aqueles que culminaram com o estabelecimento do foedus de 332, no reinado de Constantino, e que foram narrados por Paulo Orósio. ${ }^{2}$ Porém, chama-nos a atenção as informações legadas na parte final do relato orosiano com respeito à sucessão dos reges visigodos que sugerem uma tentativa de mudança na forma do exercício do poder por parte dos eleitos para a função régia. Enquanto a tríade formada por Alarico, Ataulfo e Sigerico aparece unicamente denominada com o epíteto "rei dos godos", denotando ainda uma relação primária entre o chefe militar e seus guerreiros (DIAZ MARTINEZ, 1998), com Valia surge a expressão regnum associada à sua efetiva escolha pelos godos, bem como ao estabelecimento das pazes entre godos e romanos (Or., Hist., VII, 43, 10; 43, 15). 
Hidácio complementa essa informação ao mencionar que o foedus estabelecido em 416 foi firmado entre Valia e Constancio, magister militum nos territórios ocidentais, sendo este a base da aliança entre godos e romanos que terminou por levar os primeiros a combater, em nome do Império Romano do Ocidente, os alanos e os vândalos, nas áreas ocidental e sul de Hispania (Hid., Chron., a. 416; a. 417). Como conseqüência da atitude de lealdade de Valia e dos visigodos em relação a Constâncio e aos romanos, o relato de Hidácio informa que os godos "recebem terras na Aquitania, desde Toulouse até o oceano" (Hid., Chron., a. 419). Ou seja, pela primeira vez os visigodos são mencionados pelas fontes coevas como detentores do regnum, onde a delimitação de um espaço territorial aparece como condição sine qua non para sua existência ${ }^{3}$ (VALVERDE CASTRo, 2000, p. 46).

Além disso, vale destacar outro aspecto igualmente importante: os visigodos aparecem comparados aos próprios romanos, visto que desfrutam do mesmo legado político-institucional daqueles, são detentores da monarquia clássica e do seu exercício sobre um reino espacialmente definido. Esse elo com a tradição política do passado imperial, a par com a condição de aliados do Império Romano Ocidental, retirava-lhes parte da idéia pejorativa de pertença à "barbárie", na medida em que esse conceito sofreu uma intensa readequação, entre os séculos IV e V, com a inclusão do Cristianismo niceno como diferença fundamental entre a "barbárie" e o binômio ciuilitas/christianitas (FriGHETTO, 2004a, p. 161-163).

A inserção completa dos visigodos no orbe civilizado a partir da perspectiva clássica, incluindo os elementos políticos e religiosos, deu-se, como sabemos, após a conversão do Cristianismo ariano ao niceno realizada no III Concílio de Toledo de 589, no reinado de Recaredo. E importante frisar que, mesmo durante o período visigodo ariano - desde o século IV até a segunda metade do século VI -, a construção da imagem modelar do monarca teve por base os elementos da tradição imperial romana que buscavam reforçar o caráter centralizador do poder monárquico. De fato, monarcas como Eurico ou Theudis são apresentados como responsáveis pela criação e formulação de leis, função que estava relacionada aos poderes inerentes do Imperator.

Essas características que colocavam o monarca como herdeiro e, inclusive, parceiro do imperador foram acentuadas especialmente no reinado de Leovigildo (568-586), último soberano ariano e primeiro a ser definido como rei hispano-visigodo. De acordo com Isidoro de Sevilha, Leovigildo foi "o primeiro que se apresentou aos seus com o sólio, coberto pelo vestuário real" e que "em matéria legislativa corrigiu tudo aquilo 
que parecia ter ficado confusamente estabelecido por Eurico, agregando muitas leis estabelecidas e retirando as bastante supérfluas" (Isid., Hist. Goth., 51). Tais elementos mostram a preocupação dos monarcas visigodos arianos de seguir os modelos da monarquia e do exercício do poder político vinculados à tradição imperial romana e as práticas imperiais em voga no Império Romano do Oriente. Denominadas com a expressão Imitatio Imperii (VALVERDE CASTRO, 2000), essas práticas revelam a necessidade do soberano de se destacar dos demais nobres que o apoiavam ou que eram seus rivais mais diretos. Por isso, signos visiveis desse destaque do rei em relação aos membros da nobreza começam a aparecer nas fontes, assim como as posturas e as ações do soberano mostram a tentativa, tanto do ponto de vista teórico como prático, de situá-lo como primus super pares, muito mais que a simples condição de primus inter pares.

Além do vestuário especial e da promulgação de códigos e leis, o soberano visigodo aparece também como fundador de cidades e responsável pela cunhagem de moeda (Diaz MARTINEZ, 1998), pela convocatória de reuniões conciliares do episcopado e pela condução da guerra. ${ }^{4}$ Por certo que todos esses atributos podem ser canalizados na figura de Leovigildo, desvelando um processo de centralização à volta da figura do rei que devia muito ao seu caráter enérgico e aglutinador. Há uma inequívoca tentativa de copiar e recuperar elementos que também faziam parte da tradicional imagem do poder imperial. Mas a par das construções teóricas, que após Recaredo ganharam um forte tom sacro muito acorde com a imagem imperial construída por Lactancio, Eusébio de Cesárea, Ambrósio de Milão ou Paulo Orósio, era fundamental que o monarca fosse, como Constantino ou Teodósio, um vitorioso do ponto de vista político-militar. Ao fim e ao cabo, a vitória possuía um amplo significado: o apoio divino, o talento do líder guerreiro, a força do grupo nobiliárquico que o apoiara - todos os aspectos que remetem tanto ao processo de coesão e unificação à volta do soberano como à tradição imperial romana, ou quem sabe, inclusive, à tradição consular republicana, pois Cipião Emiliano, Pompeu e César gozaram desses mesmos privilégios em seus momentos.

Notamos, portanto, que, para dimensionar o efetivo alcance do poder político exercido pelos monarcas hispano-visigodos do final do século VI e de todo o século VII, devemos levar em consideração os aspectos pragmáticos das ações realizadas pelos soberanos. Esses aspectos aparecem quase sempre vinculados às construções teóricas que os colocavam como detentores das virtudes tradicionalmente pertencentes 
à tradição imperial romana. Um caso emblemático para poder entender as dificuldades que ensejam a construção teórica e a realidade pragmática nos é apresentado por Isidoro de Sevilha, quando de sua descrição do soberano Suinthila. Monarca apresentado de forma modelar na Historia Gothorum, detentor de todas as qualidades inerentes ao bom soberano, segundo a tradição imperial romana, responsável pela conclusão da obra de unidade político-territorial iniciada por Leovigildo ao expulsar definitivamente os bizantinos da Hispania no ano de 624 (Isid., Hist. Goth., $62,63,64$ ), Suinthila aparecerá de forma completamente inversa no cânone 75 do IV Concílio de Toledo de 633, ocorrido dois anos após a sua deposição pela revolta nobiliárquica capitaneada pelo futuro rei Sisenando (FrighetTo, 1997) e presidido pelo bispo hispalense.

Uma contradição que pode estar relacionada com o deterioramento das relações amistosas entre Suinthila e grande parte da nobreza hispanovisigoda e que pode suscitar paralelismos com a deposição de Wamba em 680 (FRIGHEITo, 2004b, p. 247-251), embora sobre o primeiro tenha recaído a acusação de haver praticado atitudes tirânicas que acabaram por levar o soberano, sua esposa e seus filhos à excomunhão e à perda de todos os seus bens e títulos (Conc. IV Tol., a.633, c.75). Parece-nos certo afirmar que a vitória militar e política de Sisenando levou os bispos reunidos na assembléia conciliar a encontrarem os caminhos legais para validarem e legitimarem uma atitude, a princípio, tida como tirânica. Porém, no momento em que Isidoro de Sevilha e os demais representantes da nobreza eclesiástica hispano-visigoda apresentaram Suinthila como um autêntico tyrannus, lançando sobre ele a responsabilidade por sua derrocada, pelo fato de ter realizado ações contra o Gens Gothorum, ou seja, contra a nobreza hispano-visigoda como um todo. A velha máxima de Horácio, adaptada por Isidoro de Sevilha em suas Etimologiarum, fazia-se mais que atual para este exemplo: "rei és se agires com retidão, se não o fizeres, não serás" (Isid., Etym., IX, 3, 4).

Seguindo essa mesma linha de pensamento, por motivos um pouco distintos, encontramos no final do século VII outros indícios sugestivos da permanência de práticas e idéias teóricas e políticas que remontavam à tradição imperial romana do período do principado. De fato, quando observamos o Tomum régio encaminhado pelo monarca Égica aos bispos reunidos no XV Concílio de Toledo de 688 , notamos a sobrevivência do pensamento isidoriano na medida em que o soberano se queixa de ter sido obrigado a proclamar um duplo juramento ao seu sogro e antecessor Ervígio, que poderia levá-lo a cometer um "crime de perjúrio" (Conc. XV 
Tol., a.688, Tomum), atitude esta contrária aos preceitos virtuosos do bom soberano desde o período imperial romano. Contudo, recentemente, apresentamos outro elemento que é indiretamente citado por Égica, mas que pode ser visto como recuperação de práticas políticas comuns da época do principado (FrighetTo, 2005a): referimo-nos à prática da Adoptio entre Ervígio e Égica, tendo em vista que o primeiro, ao que tudo indica, tinha descendência varonil e não possuía um grau de parentesco direto com o segundo.

O teor existente no Tomum é muito sugestivo, pois refere-se a uma escolha dirigida do rei, contrariando a proposta isidoriana da electio entre os membros da nobreza. Claro que podemos pensar numa ampla negociação entre os vários grupos clânicos da nobreza hispano-visigoda, que chegaram a um consenso em torno do nome de Égica, o que reforçaria a idéia da ampla força política e militar por ele reunida. Diante de uma posição política mais fragilizada, vinculada provavelmente à forma de sua ascensão após o impedimentum de Wamba (Frighetto, 2002b), Ervígio buscou a associação com o grupo político de Égica, visando à manutenção dos benefícios concedidos a seus familiares e aos seus fiéis mais próximos. Abandonando a prática política do consortium, bastante utilizada pelos soberanos hispano-visigodos desde Leovigildo e ao longo do século VII, na qual associava-se o filho como co-partícipe nas tarefas de administração do reino, Ervígio, mesmo que de forma esporádica, retomou uma forma de sucessão muito comum entre os imperadores do período do principado.

\section{CONCLUSŌES PARCIAIS}

Os aspectos políticos relacionados ao exercício do poder que apresentamos neste estudo representam uma ínfima parcela do vasto universo que definimos como Antiguidade Tardia. Será que poderíamos apresentála sob o título de "Primeira Idade Média"? Com certeza sim, mas deveríamos nesse caso mudar o nosso ponto de vista de uma forma mais ampla, menos segmentada, relacionada ao processo da longa duração histórica. Como observamos, muitos elementos do binômio política-poder estavam diretamente relacionados com a tradição do passado imperial, que servia como força legitimadora para o desenvolvimento do exercício do poder.

Os soberanos tardo-antigos, visigodos e hispano-visigodos eram apresentados de maneira teórica com as virtudes e os modelos do mundo 
clássico imperial romano, além de agirem e desenvolverem uma postura política também perceptível naqueles modelos imperiais. Indubitavelmente que tanto a teoria como a prática políticas sofreram alterações em relação à sua matriz clássica primordial, pois o Cristianismo, niceno ou herético, adaptou-os aos novos tempos. Assim, notamos o estreito vínculo do Cristianismo com o Império Romano e toda a sua tradição política, que será legada, de forma perene, às monarquias romano-germânicas tardo-antigas.

Nessa linha de continuidades e permanências das práticas políticas e do exercício do poder, podemos afirmar a existência de uma Antigüidade Tardia em termos metodológicos e didáticos, pois as fontes existentes entre os séculos III e VIII sustentam essa idéia. Até mesmo esses limites cronológicos podem ser revistos, repensados e ampliados. Assim o sugere a afirmação de Paulo Orósio ao indicar a passagem da quinta à sexta era, fazendo coincidir a ascensão de Augusto com o nascimento de Cristo, uma nova etapa em que a Pax Augusta estaria relacionada ao advento do Cristianismo. Aí nasceria a relação entre o Império Romano e o Cristianismo, ou, segundo o texto orosiano, os Tempora Christiana. ${ }^{5}$ Novas perspectivas, novos olhares, sejam eles voltados à Antiguidade Tardia ou à "Primeira Idade Média".

\section{POLITICS AND POWER IN LATE ANTIQUTYY: A POSSIBLE STUDY}

ABstRaCT: Late Antiquity or First Medieval Age? The present study intends to show, through an analysis of the aspects linked to the binomial concept of politics and power, the feasibility of the application of the concept "Late Antiquity" for the period of transition between the medieval and classical worlds, that is, between the centuries III and VIII AC.

KEY WORDS: Late Antiquity, classical and imperial tradition, roman-germanic monarchies.

\section{NOTAS}

1. A título de exemplo do ponto de vista político, ver Tac., Germ, 7; 14. 1. Em Pacato, a unidade política do mundo imperial culminava na figura do imperador de origem hispana, enquanto, em Isidoro, a unidade política do reino hispanovisigodo havia sido alcançada pelo vitorioso Suinthila.

2. Or., Hist. Adv. Pag., VII, 28; muito provavelmente seja esta também uma referência feita por Zos., Hist., II, 34 .

3. Definição claramente apresentada por Isid.,Etym., IX, 3,2: “[...] Regnum universae nationes [...] locis inter se ordinata atque distincta $[\ldots .$.$] ".$ 
4. Essas atitudes são apresentadas por Ioan. Bicl., Chronc., a.573,5; a.574,2; a.575,2; a. 576,$3 ;$ a. 577,$2 ; a .578,4 ; a .580,2$.

5. Or., Hist. Adv. Pag., VI, 22, 9-10; na mesma perspectiva apresentada por Isid., Chronc, , 85-86.

\section{REFERÊNCIAS}

\section{A) Documentação primária impressa}

Ael. Spart., Vit. Hadr = Aelio Spartiano, De Vita Hadriani. Introdução, transcrição e tradução de David Magie, Historia Augusta Volume I - Loeb Classical Library, Cambridge, 1991. p. 2-81.

Aur. Vic., De Caesaribus = Aurélo Victor, De Caesaribus. Introdução, tradução e notas de Emma Falque, Eutropio. Breviario. Aurelio Victor. Libro de los Césares Biblioteca Clásica Gredos 261, Madrid, 1999. p. 187-252.

Conc IV Tol. $=$ IV Conctlio DE TOLEDO. Edição preparada por José Vives, Concilios Visigoticos e Hispano romanos, Barcelona-Madrid, 1963. p. 186-224.

Conc. XV Tol. $=$ XV Conctlio DE Toledo. Edição preparada por José Vives, Concilios Visigoticos e Hispano romanos, Barcelona, Madrid, 1963. p. 449-474.

Flav. Vop., Div. Aurel = Flavıo Vopisco, Divus Aurelianus. Introdução, transcrição e tradução de David Magie, Historia Augusta Volume III - Loeb Classical Library, Cambridge, 1998. p. 192-293.

Herod., Hist. $=$ Heródoto, Historia . Tradução e notas por Carlos Schrader, Heródoto. Historia Libro VII - Biblioteca Clásica Gredos 82, Madrid, 1991.

Hid., Chron. = Hidacio DE CHAVEs, Chronicon. Estudo, edição crítica e tradução de Julio Campos, Cronicon de Idacio, obispo de Chaves (s.IV-V), Salamanca, 1984. p. 40135.

Iul. Cap., Max. Duo = Julı CAPitolino, Maximini Duo. Introdução, transcrição e tradução de David Magie, Historia Augusta Volume II - Loeb Classical Library, Cambridge, 1993. p. 314-79.

Isid., Hist. Goth. = Isidoro DE SEvilHA, Historia Gothorum. Estudo, edição crítica e tradução de Cristóbal Rodríguez Alonso, Las Historias de los Godos, Vandalos y Suevos de Isidoro de Sevilla, Leon, 1975. p. 172-281.

Isid., De Laud. Span. =ISIDORo de Sevilha, De Laude Spaniae. Estudo, edição crítica e tradução de Cristóbal Rodríguez Alonso, Las Historias de los Godos, Vandalos y Suevos de Isidoro de Sevilla, Leon, 1975. p. 168-71.

Isid.,Etym. = IsIDORO DE SEVILHA, Etymologiarum libri XX. Estudo, edição crítica $\mathrm{e}$ tradução de Jose Oroz Reta e Manuel A. Marcos Casquero, San Isidoro de Sevilla. Etimologías. Edición bilingüe, Madrid, 1982,2v. 
Isid., Chronc. $=$ Isidoro DE SevilhA, Chronicon. Edição de J. P. Migne, Patrologiae LatinaeTtomus LXXXIII, Paris, 1862. p. 1017-1058.

Ioan. Bicl, Chronc. = JOAO DE BICLARO, Chronicon. Introdução, texto crítico e comentários de Julio Campos, Juan de Biclaro. Obispo de Gerona. Su vida y su obra, Madrid, 1960. p. 77-100.

Lact., De Mort. Persec. = LACTANCIO, De Mortibus Persecutorum. Introdução, tradução e notas de Ramón Teja, Lactancio. Sobre la muerte de los perseguidores - Biblioteca Clásica Gredos 46, Madrid, 1982.

Or., Hist. Adv. Pag. = Paulo Orosio, Historiarum Adversvm Paganos Libri VII. Edição e transcrição de Karl Zangmeister, Heidelberg, 1881.

Pac., Paneg. Theod $=$ PACATo DrepANI, Panegyricts Theodosio Augusto dictus, Estudo, edição e tradução por Edouard Galletier, Panégyriques Latins. Tome III (XI-XII), Paris, 1955. p. 67-114.

Zos., Hist. = Zosimo, Historia Nova. Introdução, tradução e notas de José M.Candau Morón, Zosimo. Nueva Historia - Biblioteca Clásica Gredos, Madrid, 1992.

\section{B) Obras de apoio}

ANDRE,J. M.; HUS, A. L'Histoire d̀ Rome: historiens et biographes dans la littérature latine. Paris: Press Universitaires de France, 1974.

Bruvo, G. El ritual de la 'proskinesis' y su significado político y religioso en la Roma imperial (con especial referencia a la Tetrarquía). Gerión, Madrid, v. 15, p. 177-191, 1997.

CAZIER, Pierre. Les Sentences d'Isidore de Seville et le Ive Concile de Tolede. Réflexions sur les rapports entre l'Eglise et le pouvoir politique en Espagne autour des années 630. Los visigodos: historia y civilización - antiguedad y cristianismo III, Murcia, 1986. p. 373-386.

Diaz Martínez, Pablo. Rey y poder en la monarquía visigoda. Iberia, Logroño, v. 1, p. 175-195, 1998.

Escribano, Maria Victoria. Usurpación y religión en el siglo IV D. de C. Paganismo, cristianismo y legitimación política. Cristianismo y aculturación en tiempos del Imperio Romano: antiguedad y cristianismo VII. Murcia, 1990. p. 247-272.

Finley, Moses. A política no mundo antigo. Rio de Janeiro: Zahar, 1985.

FonTAINE, Jacques. Isidoro de Sevilla: Génesis y originalidad de la cultura hispánica en tiempos de los visigodos. Madrid, 2002.

Frighetro, Renan. Aspectos da teoria política isidoriana: o cânone 75 do IV Concílio de Toledo e a constituição monárquica do reino visigodo de Toledo. Revista de Ciências Históricas, Porto, n. 12, p. 73-82, 1997.

2000. Cultura e poder na Antiguidade Tardia Ocidental. Curitiba: Juruá Editora, 

p. 491-509.

Infidelidade e Barbárie na Hispania Visigoda. Gerión 20-1. Madrid, 2002a,

Legitimidade e usurpação na Hispania visigoda de finais do século VII: o caso do reinado de Wamba (672-680). In: Santos Crespo Ortiz de Zárate \& Ángeles Alonso Ávila (Orgs.) Scripta Antiqua in honorem Ángel Montenegro Duque et José María Blázquez Martínez). Valladolid, 2002b, p. 841-849.

Da Antiguidade Clássica à Idade Média: a idéia de Humanitas na Antiguidade Tardia Ocidental. Temas Medievales 12, Buenos Aires, 2004a, p. 147-163.

Uma confrontação régio-nobiliárquica na Antiguidade Tardia hispanica: o rei e a nobreza eclesiástica no reinado de Wamba (672-680). Semanas de Estudios Romanos XII. Viña del Mar, 2004b, p. 233-252.

Algumas considerações sobre o poder político na Antiguidade Clássica e na Antiguidade Tardia. Stylos 13. Buenos Aires, 2004c, p. 37-48.

. Aspectos teóricos e práticos da legitimidade do poder régio na Hispania visigoda: o exemplo da Adoptio. Cuadernos de Historia de España LXXIX. Buenos Aires, 2005a, p. 237-45.

A imagem de Teodósio nas Historiae Adversum Paganus VII, 34-35 de Paulo Orósio. Stylos 14. Buenos Aires, 2005b (inédito).

$\mathrm{O}$ exercício do poder régio entre os visigodos nos primórdios do século $\mathrm{V}$ : a sucessão régia e a herança baixo-imperial romana. Revista Caesaraugusta 77. Zaragoza, 2005c (inédito).

Garcia moreno, Luís Agustín. Historia de España Visigoda. Madrid: Ediciones Catedra, 1989.

MArrou, Henri Irineé. Saint Augustin, Orose et l'Augustinisme historique. La storiografia Altomedievale - Settimane di studio del Centro Italiano di studi sullalto medioevo XVII. Spoleto, 1970. p. 60-87.

Momigliano, Arnaldo. L'Etá del trapasso fra storiografia antica e storiografia medievale (320-550 D.C.). La storiografia Altomedievale - Settimane di studio del Centro Italiano di studi sullalto medioevo XVII. Spoleto, 1970. p. 89-118.

Perez SANCHeZ, Dionisio. El ejército en la sociedad visigoda. Salamanca: Ediciones Universidad de Salamanca, 1989.

Rodriguez Alonso, Cristobal. Las Historias de los Godos, Vandalos y Suevos de Isidoro de Sevilla - Estudio, Edición Critica y Traducción. Leon: Colegiata de San Isidoro, 1975.

Rouche, Michel. L'Aquitaine des Wisigoths aux Arabes. Naissance d'une région. Paris: Ėditions de L'Ècole des Hautes Etudes en Sciences Sociales, 1979.

STRAuB, Johannes. Conciencia de Imperio y sentimiento nacional en las provincias romanas. Hispania y el Imperio Romano en la concepción de Floro. Cristianismoy 
aculturación en tiempos del Imperio Romano - Antiguedad y Cristianismo VII. Murcia, 1990, p. 649-667.

TEjA, Ramon. El ceremonial en la corte del Imperio Romano tardío. Emperadores, obispos, monjes y mujeres. Protagonistas del Cristianismo antiguo. Madrid: Editorial Trotta, 1999, p. 39-71.

VALVERDE CASTRO, Maria del Rosario. Ideología, simbolismo y ejercicio del poder real en la monarquía visigoda: un proceso de cambio. Salamanca: Ediciones Universidad de Salamanca, 2000. 